\title{
Effect of EDTA on TGF- $\beta 1$ released from the dentin matrix and its influence on dental pulp stem cell migration
}

Lidiany Freitas GONÇALVES(a)

Ana Paula FERNANDES(b) Leopoldo COSME-SILVA ${ }^{(a)}$ Fabio Antonio COLOMBO(c) Natália Silva MARTINS(d) Thais Marchini OLIVEIRA ${ }^{(b)}$ Tomaz Henrique ARAUJO(e) Vivien Thiemy SAKAI(a)

(a) Universidade Federal de Alfenas, School of Dentistry, Department of Clinics and Surgery, Alfenas, MG, Brazil.

(b) Universidade de São Paulo - USP, Bauru School of Dentistry, Department of Pediatric Dentistry, Orthodontics and Public Health, Bauru, SP, Brazil.

(c) Universidade Federal de Alfenas, Institute of Biomedical Sciences, Department of Pathology and Parasitology, Alfenas, MG, Brazil.

(d) Universidade Federal de Alfenas, Institute of Exact Sciences, Alfenas, MG, Brazil.

(e) Universidade Federal de Alfenas, Institute of Biomedical Sciences, Department for Cell, Tissue and Developmental Biology, Alfenas, MG, Brazil.

Declaration of Interests: The authors certify that they have no commercial or associative interest that represents a conflict of interest in connection with the manuscript.

\section{Corresponding Author:}

Vivien Thiemy Sakai

E-mail:vivienodonto@yahoo.com

DOI: 10.1590/1807-3107BOR-2016.vol30.0131

Submitted: Feb 29, 2016

Accepted for publication: Sep 23, 2016

Last revision: Oct 04, 2016

\begin{abstract}
Bioactive molecules stored in dentin, such as transforming growth factor beta1 (TGF- $\beta 1$ ), may be involved in the signaling events related to dental tissue repair. The authors conducted an in vitro evaluation of the amount of TGF- $\beta 1$ released from dentin slices after treatment with 10\% ethylenediaminetetraacetic acid (EDTA), 2.5\% sodium hypochlorite $(\mathrm{NaOCl})$ or phosphate-buffered saline (PBS), and the effect of this growth factor on stem cell migration from human exfoliated deciduous teeth (SHED). Sixty 1-mm-thick tooth slices were prepared with or without the predentin layer, and treated with either $10 \%$ EDTA for 1 minute, $2.5 \% \mathrm{NaOCl}$ for 5 days or kept in PBS. Tooth slice conditioned media were prepared and used for TGF- $\beta 1$ ELISA and migration assays. Culture medium with different concentrations of recombinant human TGF- $\beta 1(0.5,1.0,5.0$ or $10.0 \mathrm{ng} / \mathrm{mL})$ was also tested by migration assay. The data were evaluated by ANOVA and Tukey's test. Optical density values corresponding to media conditioned by tooth slices either containing or not containing the predentin layer and treated with 10\% EDTA were statistically greater than the other groups and close to $1 \mathrm{ng} / \mathrm{mL}$. Increased rates of migration toward media conditioned by tooth slices containing the predentin layer and treated with PBS, 10\% EDTA or $2.5 \% \mathrm{NaOCl}$ were observed. Recombinant human TGF- $\beta 1$ also stimulated migration of SHED, irrespective of the concentration used. EDTA may be considered an effective extractant of TGF- $\beta 1$ from the dentin matrix. However, it does not impact SHED migration, suggesting that other components may account for the cell migration.
\end{abstract}

Keywords: Cell movement; Dentin; Transforming growth factor beta1.

\section{Introduction}

Regenerative endodontics by revascularization and tissue-engineering strategies have gained increased attention. Several studies have focused on the regenerative potential of different cytokines and growth factors designed to improve cellular chemotaxis and cell homing into the emptied dental pulp space in vivo. ${ }^{1,2,3,4,5,6}$ The dentin matrix is a reservoir of soluble cytokines and growth factors secreted by odontoblasts and pulp fibroblasts, which could be released during tissue demineralization. ${ }^{1,2,3,4}$ The dissolution of these cytokines and growth factors can occur pathologically during dental caries and following restorative procedures. ${ }^{2,3}$ Notably, during severe pulp disease or trauma, primary odontoblasts may not survive, and formation of a 
new population of odontoblast-like cells for reparative dentinogenesis and bridge formation will require the attraction and recruitment of stem/progenitor cells to the injury site. ${ }^{5}$

One such potential chemoattractant for stem cells includes transforming growth factor $\beta 1$ (TGF- $\beta 1$ ). TGF- $\beta 1$ may be involved in signaling events related to the proliferation, differentiation and recruitment of stem/progenitor cells to the site of tooth injury, in order to initiate regeneration, thus acting as a stimulating factor for dental tissue repair. . $7,8,9,10,11,12$ From a clinical perspective, the use of appropriate irrigation solutions could release the TGF- $\beta 1$ stored in the dentin, thus contributing to successful regenerative endodontic treatment by directing cellular fate. ${ }^{4}$

Two irrigants currently used during cleaning and shaping of the root canal are ethylenediaminetetraacetic acid (EDTA) ${ }^{13}$ and sodium hypochlorite $(\mathrm{NaOCl}){ }^{14,15,16,17}$ EDTA is a final irrigant that causes dentin demineralization and provides excellent cleaning of the canal walls. ${ }^{13}$ It acts on the inorganic components of the smear layer, leading to decalcification of the peri- and intertubular dentin. It also covalently binds to metal ions and sequesters calcium ions present in hydroxyapatite dentin. ${ }^{18} \mathrm{NaOCl}$ is an auxiliary irrigant that is used during root canal instrumentation to promote debridement, lubrication, disinfection, tissue dissolution, collagen layer removal and dentin dehydration ${ }^{14,15,16}$ and that also causes protein denaturation. ${ }^{17}$

EDTA conditioning of dentine promotes adhesion, migration and differentiation of the pulp stem cells from permanent teeth. ${ }^{3}$ In addition, various soluble proteins extracted from the dentine matrix are able to exert a direct biological effect on dental pulp stem cells in promoting mineralized tissue repair mechanisms. ${ }^{19}$ Nevertheless, the amount of TGF- $\beta 1$ released from dentin by different irrigants used in endodontic procedures (such as EDTA and $\mathrm{NaOCl}$ ) has not been clearly established. Moreover, current knowledge regarding the effect of TGF- $\beta 1$ on stem cells from human exfoliated deciduous teeth (SHED) and the relative potency of TGF- $\beta 1$ in promoting the attraction of these cells is limited. Therefore, the purpose of the present study was to make an in vitro evaluation of the amount of TGF- $\beta 1$ released from dentin slices after their treatment with 10\% EDTA in comparison with $2.5 \% \mathrm{NaOCl}^{4,17}$ or phosphate-buffered saline (PBS), and the effect of this growth factor on the migration of stem cells from human exfoliated deciduous teeth (SHED).

\section{Methodology}

\section{Tooth slice preparation}

The experiments were undertaken with the understanding and written consent of all the subjects and in full accordance with ethical principles. The study was reviewed independently and approved by the ethical board of our institution (Protocol \# 040/2011). Forty extracted non-carious human third molars were collected in the surgery clinics of our institution. Residual soft tissues were removed with a periodontal curette, and the dental surfaces were wiped down with $70 \%$ ethanol. The teeth were then cut transversally in the cervical region with a diamond-edged blade at low speed under cooling with sterile PBS to obtain slices 1-mm thick and a wide pulp chamber. ${ }^{20,21,22}$ The pulp tissue was carefully pulled away with tissue forceps, without touching the predentin layer, which could be visually identified by its whitish color in comparison with the yellow dentin.

The thin whitish layer (predentin) was kept untouched in half of the tooth slices $(n=30)$ and removed from the other half $(n=30)$ with one half the diameter of the bur head (FG 2134, KG Sorensen, Cotia, Brazil), i.e. $0.7 \mathrm{~mm}$, under refrigeration (Figure 1). All of the samples were disinfected with ethanol in decreasing concentrations (100-70\%) and stored in sterile PBS.

\section{Tooth slice conditioned media preparation}

Tooth slices both containing and not containing the predentin layer were treated with either 10\% EDTA for 1 minute, $2.5 \% \mathrm{NaOCl}$ for 5 days or kept in PBS. Each tooth slice was transferred to 24-well plates containing $500 \mathrm{~mL}$ of alpha-MEM (Gibco, Invitrogen, Grand Island, USA), supplemented with $10 \%$ fetal bovine serum (FBS, Fetal Bovine Serum, certified, heat-inactivated, Gibco, Invitrogen, Grand Island, 

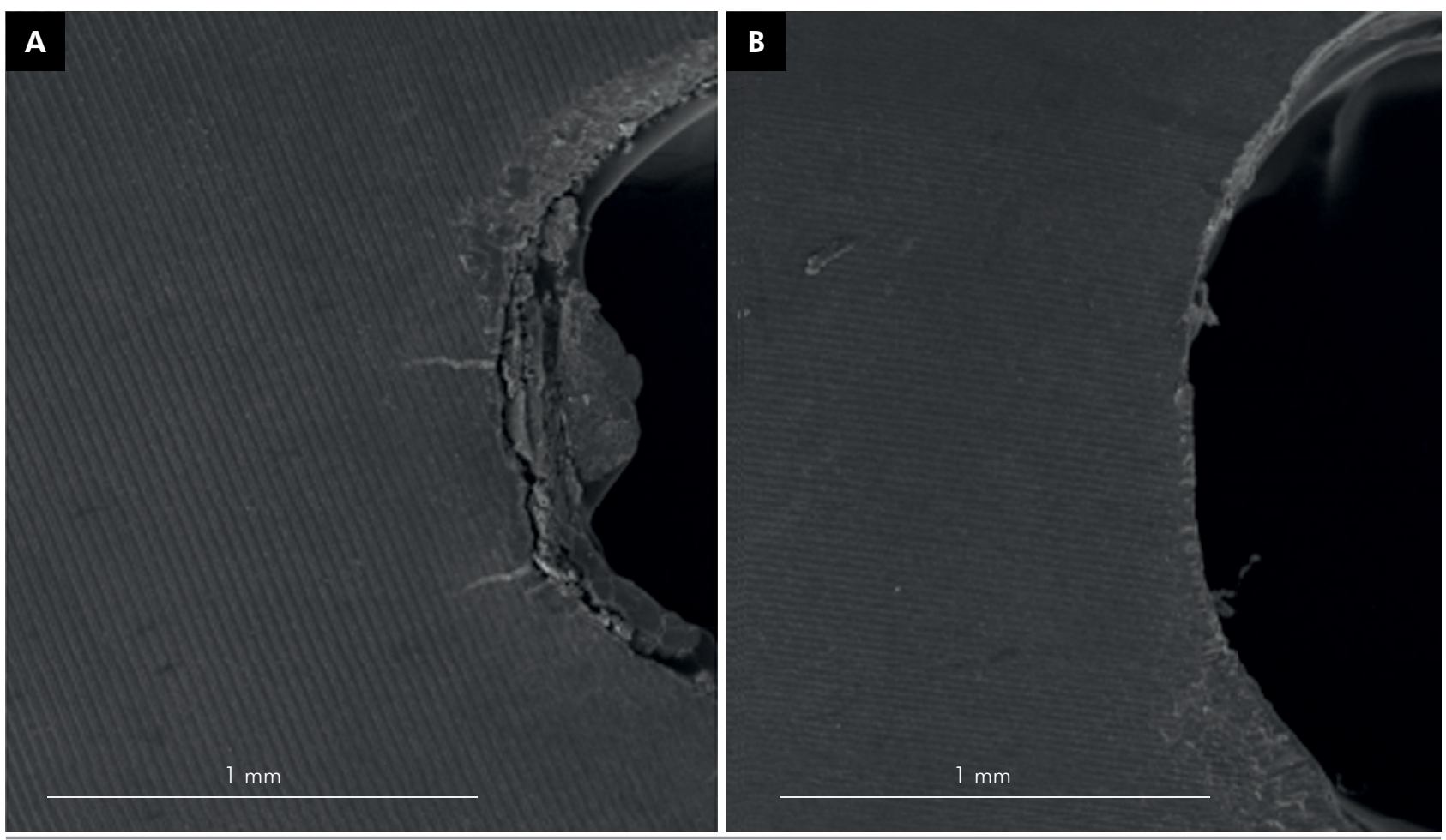

Figure 1. Scanning electron microscopy images of the tooth slices used in the study (magnification 95X). A) With the predentin layer. B) Without the predentin layer.

USA) and 1\% penicillin and streptomycin solution (Penicillin-Streptomycin, Gibco, Invitrogen, Grand Island, USA). The plates were incubated at $37^{\circ} \mathrm{C}$ for 3 days and the tooth slice conditioned media were collected for enzyme-linked immunosorbent assay (ELISA) and migration assay.

\section{ELISA assay}

An ELISA kit was used to quantify the TGF- $\beta 1$, according to the manufacturer's instructions (Quantikine; R\&D Systems, Minneapolis, USA). A standard curve was created with the serially diluted TGF- $\beta 1$ provided in the kit. Optical density was immediately determined using a spectrophotometer at $450 \mathrm{~nm}$. The data were linearized by plotting the $\log$ of the TGF- $\beta 1$ concentrations versus the $\log$ of the optical density. TGF- $\beta 1$ concentrations were determined by linear regression. Each sample was assayed in triplicate.

\section{Cell culture}

The SHED, kindly provided by Dr. Bruno N. Cavalcanti (DDS, MSc, PhD, Institute of Science and Technology, São Paulo State University, São José dos Campos, Brazil), were isolated by standard enzymatic digestion protocol and characterized according to Miura et al., ${ }^{23}$ after Institutional Review Board approval (CAAE 02210312.1.0000.0077). TheSHED were cultured in alpha-MEM supplemented with $10 \%$ fetal bovine serum and $1 \%$ penicillin and streptomycin solution. The cells were maintained in the incubator at $37^{\circ} \mathrm{C}$ and $5 \% \mathrm{CO}_{2}$, and split at a ratio of $1: 3$ when they reached $80 \%$ confluence. The medium was changed every three days. The SHED were used at passages 5 to 7 .

\section{Cell migration assay}

Each well of a 24-well companion plate (Fisher Scientific, Pittsburgh, USA) was loaded with $500 \mathrm{~mL}$ of either the medium conditioned by the tooth slices containing or not containing the predentin layer and treated with $10 \%$ EDTA, $2.5 \% \mathrm{NaOCl}$ or PBS, or the medium supplemented with $20 \%$ FBS (Control 1) or 10\% FBS (Control 2). Twenty-four-hour serum-starved SHED $\left(2 \times 10^{4}\right)$ were seeded onto $8 \mathrm{~mm}$-pore-sized inserts in $200 \mathrm{~mL}$ of culture medium 
and allowed to migrate toward the conditioned media or controls overnight. The inserts were removed and the migrated cells were trypsinized, collected in microcentrifuge tubes and centrifuged at $3,835 \times \mathrm{g}$ at $4^{\circ} \mathrm{C}$ for 10 minutes. The pellets were washed with PBS and centrifuged at $3,835 \times \mathrm{g}$ at $4^{\circ} \mathrm{C}$ for 5 minutes. After removing the supernatant, the pellets were transferred to a new 24-well plate with $500 \mathrm{~mL}$ of PBS and $20 \mathrm{mM}$ Cell Tracker ${ }^{\mathrm{TM}}$ Green CMFDA (Invitrogen, Carlsbad, USA). The plate was covered with aluminium foil and incubated for 30 minutes. Fluorescence was read at $485 \mathrm{~nm}$. The numbers relate to arbitrary units of transwell-migrating cells, as determined by fluorescent analysis of three separate wells for each treatment.

A second migration assay was performed using different concentrations of recombinant human TGF- $\beta 1(0.5,1.0,5.0$ and $10.0 \mathrm{ng} / \mathrm{mL})$ instead of the conditioned media as a chemoattractant for the cells, using the same protocol described above.

\section{Statistical analysis}

Statistical analysis was performed using $\mathrm{R}$ statistical software. The data were tested for normality and analyzed by analysis of variance (ANOVA), followed by Tukey's test. Differences were considered significant at $p<0.05$. The data were expressed as mean value and standard deviation.

\section{Results}

ELISA results for detection of TGF- $\beta 1$ in the experimental groups, and their comparison with known concentrations of serially diluted TGF- $\beta 1$ antibody, are seen in Figure 2A and Figure 2B. Figure $2 \mathrm{C}$ shows the comparison of the optical densities among the groups measured with a spectrophotometer for detection of TGF- $\beta 1$ released in the culture medium. The optical density values corresponding to the media conditioned by tooth slices either containing or not containing the predentin layer and treated with 10\% EDTA were statistically greater than those of the other groups $(p<0.05)$. No differences were seen among the groups treated with $2.5 \% \mathrm{NaOCl}$ and PBS.

Table 1 presents the estimated concentration of TGF- $\beta 1$ in each group, calculated by linear regression $(y=a x+b)$, where $y$ is the estimated concentration of TGF- $\beta 1, x$ is the optical density, $a=0.0021$ and $\mathrm{b}=0.1401$. The standard curve presented great

A
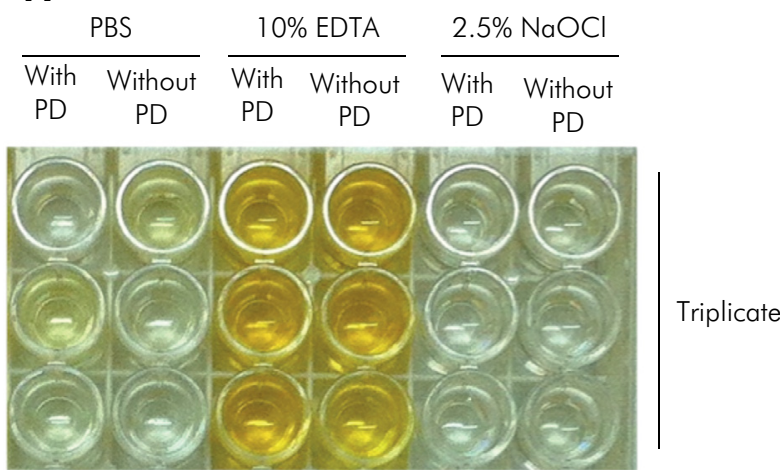

B

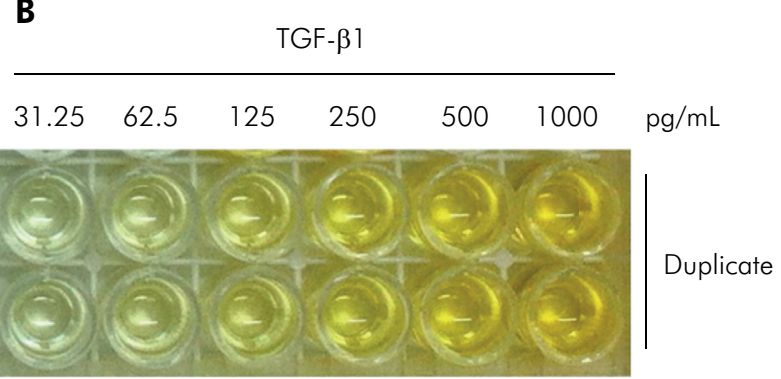

C

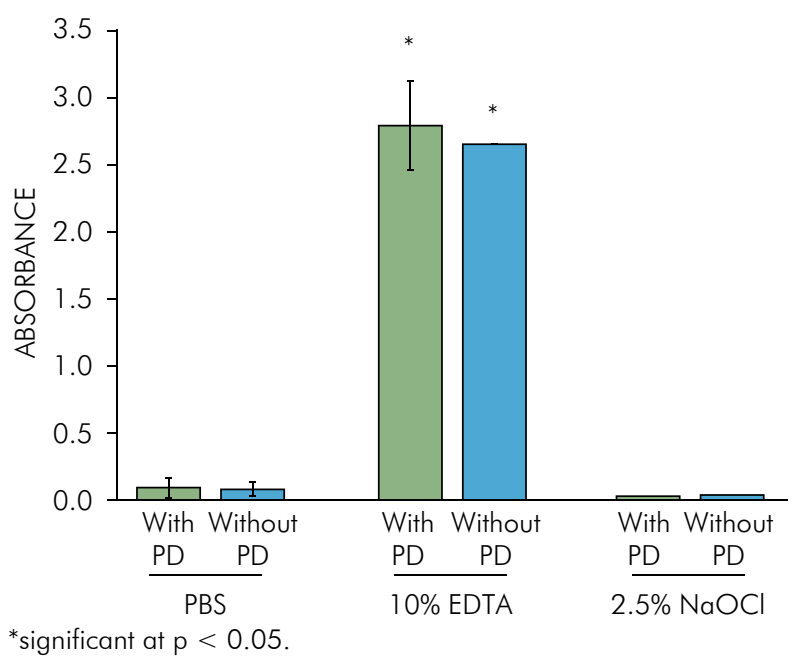

Figure 2. Enzyme-linked immunosorbent assay (ELISA) for detection of TGF-b1. A) TGF-b1 released in the culture medium by tooth slices either containing or not containing the predentin layer (PD) and treated with PBS, $10 \%$ EDTA or $2.5 \% \mathrm{NaOCl}$, B) compared with serially diluted TGF-b 1 antibody. C) Optical density at $450 \mathrm{~nm}$ measured on an ELISA reader for detection of TGF-b1 released in the culture medium by tooth slices either containing or not containing the predentin layer (PD) and treated with PBS, $10 \%$ EDTA or $2.5 \% \mathrm{NaOCl}$. 
linearity and reproducibility, with $\mathrm{R}^{2}=0.974$, indicating good correlation between the variables analyzed. The concentrations of TGF- $\beta 1$ in the groups treated with $10 \%$ EDTA were close to $1 \mathrm{ng} / \mathrm{mL}$.

Statistically significant differences were detected between the rates of migration toward the medium conditioned by tooth slices containing the predentin layer, in comparison with those without the predentin layer, for each treatment performed ( $p<0.05$, Figure 3$)$. Increased rates of migration toward Control 1 and the media conditioned by tooth slices containing the predentin layer and treated with PBS, 10\% EDTA or $2.5 \% \mathrm{NaOCl}$ were observed, with no difference among these groups $(p>0.05)$. Lower rates were seen for cells migrating toward Control 2 and the media

Table 1. Estimated TGF- $\beta 1$ concentration $(\mathrm{pg} / \mathrm{mL})$ in the medium conditioned by tooth slices either containing or not containing the predentin layer (PD) and treated with PBS, 10\% EDTA or $2.5 \% \mathrm{NaOCl}$.

\begin{tabular}{|c|c|c|c|c|c|c|}
\hline \multirow[b]{2}{*}{ Variable } & \multicolumn{2}{|c|}{ PBS } & \multicolumn{2}{|c|}{$10 \%$ EDTA } & \multicolumn{2}{|c|}{$2.5 \% \mathrm{NaOCl}$} \\
\hline & $\begin{array}{l}\text { With } \\
\text { PD }\end{array}$ & $\begin{array}{c}\text { Without } \\
\text { PD }\end{array}$ & $\begin{array}{l}\text { With } \\
\text { PD }\end{array}$ & $\begin{array}{c}\text { Without } \\
\text { PD }\end{array}$ & $\begin{array}{l}\text { With } \\
\text { PD }\end{array}$ & $\begin{array}{c}\text { Without } \\
\text { PD }\end{array}$ \\
\hline TGF-bl & $M C$ & $M C$ & $1.262 .175^{*}$ & $1.197 .095^{*}$ & $M C$ & $M C$ \\
\hline
\end{tabular}

$\mathrm{MC}=$ minimal concentration or zero; ${ }^{*}$ significant at $\mathrm{p}<0.05$.

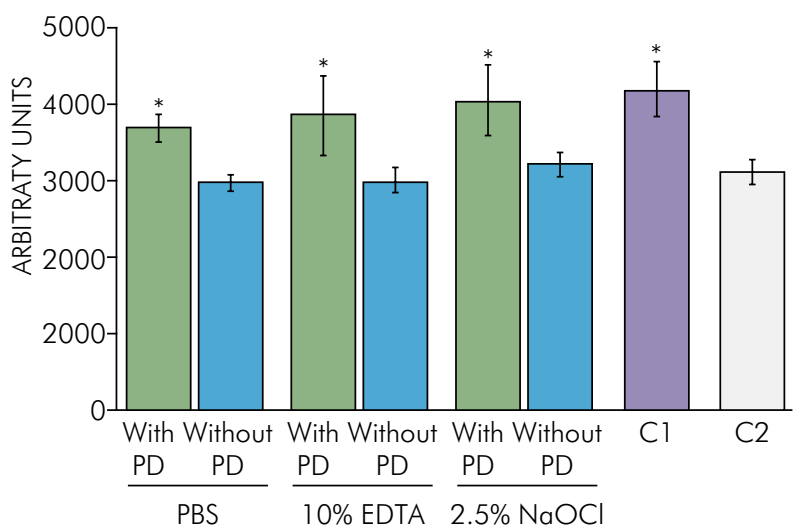

*significant at $p<0.05$

Figure 3. SHED migration through 8-mm-pore membranes toward the media conditioned by tooth slices either containing or not containing the predentin layer (PD) and treated with PBS, $10 \%$ EDTA or $2.5 \% \mathrm{NaOCl}$, or toward alpha-MEM supplemented with $20 \%$ FBS (Control 1 - C 1) or 10\% FBS (Control 2 - C 2). conditioned by tooth slices without the predentin layer, with no difference among the three treatments performed $(p>0.05)$.

The migration ability of SHED toward the media containing different concentrations of recombinant human TGF- $\beta 1$ is seen in Figure 4. Increased migration rates were detected in the groups containing TGF- $\beta 1$, irrespective of the concentration used, in comparison with controls 1 and $2(\mathrm{p}<0.05)$.

\section{Discussion}

Pulp tissue injury from dental trauma and caries in teeth with incomplete apical development have provided unique opportunities to explore the regenerative potential in endodontics. It is believed that, if the revascularization or the engineering of a vital pulp could induce root extension and radicular reinforcement, the root canal could be chemically and/or mechanically treated to enable elimination of microorganisms, tissue dissolution and removal of debris and organic components of the smear layer. In order to produce new dentin, stem/progenitor cells would have to migrate toward the treated dentine walls, proliferate and differentiate into odontoblasts. ${ }^{4}$ In the present study, we used tooth slices with and without the predentin layer, and chemical agents typically employed as root canal irrigants ( $\mathrm{NaOCl}$ and EDTA), to test if the

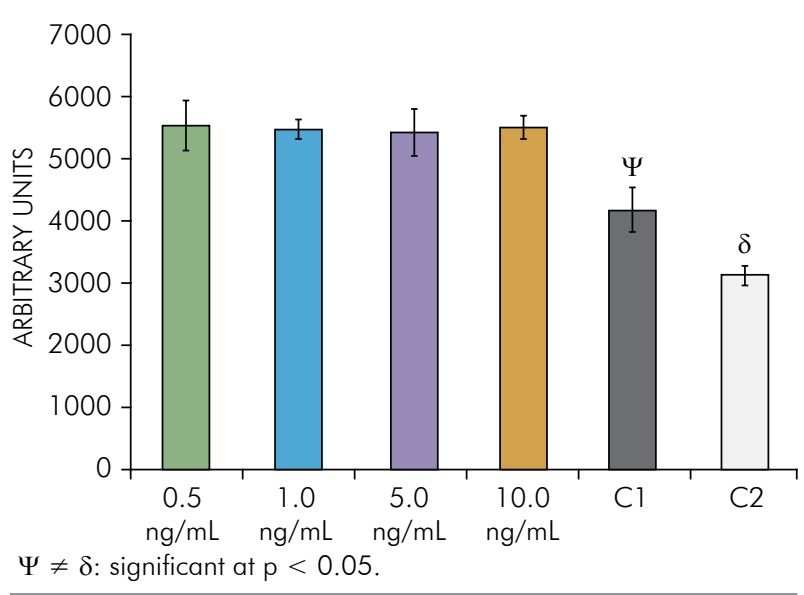

Figure 4. SHED migration through 8-mm-pore membranes toward the media conditioned by different concentrations of TGF-b 1, or toward alpha-MEM supplemented with 20\% FBS (Control 1 - C 1) or 20\% FBS (Control 2 - C 2). 
pretreatment of dentin tooth slices could interfere with the SHED migration process.

The choice of EDTA and $\mathrm{NaOCl}$ was based on their widespread use in the solubilization of the dentin matrix and mineral components from the smear layer. ${ }^{4,8}$ In contrast, PBS was chosen due to its inability to properly dissolve the mineral or organic components of dentin. ${ }^{4,8}$ Considering that $\mathrm{NaOCl}$ denatures proteins found in the dentin matrix ${ }^{17}$ we employed this solution for five days to remove the organic content from dentin in an attempt to eliminate the effect of dentin matrix molecules on SHED. As expected, EDTA was a significantly more effective extractant of TGF- $\beta 1$ than PBS and NaOCl. This is most likely attributed to its powerful demineralizing and solubilizing action on hard dental tissues. ${ }^{2}$ In contrast, a smaller amount of TGF-b1 was found in the $\mathrm{NaOCl}$ treatment samples. Although our data broadly corroborate those of other studies showing that EDTA conditioning of dentine promotes migration of dental pulp stem cells, ${ }^{3}$ we noticed differences in relation to published data regarding cell migration toward alpha-MEM supplemented with 20\% FBS (Control 1). Whereas our study found that the rates of migration toward the media conditioned by tooth slices containing predentin layer and treated with 10\% EDTA were similar to those of Control 1, ${ }^{3}$ Galler et al. (2016) found that cell migration toward the pretreated dentine surface amounted to $70 \%$ of the positive migration control (alpha-MEM with 20\% FBS). This variation may be explained (at least in part) by the use of cell types different from SHED.

The ability of chemical treatment with root canal irrigants to unmask TGF- $\beta 1$ epitopes on the matrix surface ${ }^{8}$ has important implications for pulp revascularization and pulp tissue engineering, since this treatment could facilitate TGF- $\beta 1$ mediated reparative and/or regenerative processes at the injury sites. Our results demonstrate that appropriate dentin treatment can optimize exposure of endogenous TGF- $\beta 1$, which may be important to provide a signaling mechanism for stem/progenitor cell migration $^{24}$ and odontoblast-like cell differentiation ${ }^{18}$. However, little information is available as of yet on the signals involved in the migration that precedes reparative dentin synthesis. ${ }^{15}$

The present study demonstrated that SHED migration was not influenced by the tooth slice treatment, but rather by the presence or absence of the predentin layer. Considering that minimal or no instrumentation of the dentinal walls is recommended for dental pulp revascularization procedures, ${ }^{25}$ our results suggest that no instrumentation is preferable since the soluble proteins would remain available in the untouched predentin layer, so as to be extracted and exert biological effects on dental pulp stem cells. Interestingly, recombinant human TGF- $\beta 1$ stimulated SHED migration, corroborating the results by Mathieu et al,. ${ }^{24}$ who observed that TGF- $\beta 1$ acted as a potent chemotactic factor of STRO-1-sorted cells, although this event was not concentration-dependent in our study.

The fact that the use of EDTA promoted significant TGF- $\beta 1$ release, but did not increase SHED migration, suggests that other signaling molecules may also be mobilized from dentin and impair the TGF- $\beta 1$ effect on SHED migration. Additionally, the increased migration ability of SHED toward the media conditioned by tooth slices containing the predentin layer, in comparison with that toward the media conditioned by tooth slices without the predentin layer, irrespective of the treatment performed, may be attributed to the enhanced mobilization of bioactive substances other than TGF- $\beta 1$ from the non-mineralized predentin versus the mineralized dentin.

\section{Conclusion}

EDTA is a more effective extractant of TGF- $\beta 1$ from the dentin matrix than $\mathrm{NaOCl}$ or PBS. However, the release of TGF- $\beta 1$ from the dentin matrix by EDTA treatment does not impact SHED migration, suggesting that other components may account for the cell migration.

\section{Acknowledgements}

This study was funded by FAPEMIG (APQ-00215-11 and PPM-00146-13). 


\section{References}

1. Howard C, Murray PE, Namerow KN. Dental pulp stem cell migration. J Endod. 2010;36(12):1963-6. doi:10.1016/j.joen.2010.08.046

2. Tomson PL, Lumley PJ, Alexander MY, Smith AJ, Cooper PR. Hepatocyte growth factor is sequestered in dentine matrix and promotes regeneration-associated events in dental pulp cells. Cytokine. 2013;61(2):622-9. doi:10.1016/j.cyto.2012.11.009

3. Galler KM, Widbiller M, Buchalla W, Eidt A, Hiller KA, Hoffer PC et al. EDTA conditioning of dentine promotes adhesion, migration and differentiation of dental pulp stem cells. Int Endod J. 2016;49(6):581-90. doi:10.1111/iej.12492

4. Galler KM, Buchalla W, Hiller KA, Federlin M, Eidt A, Schiefersteiner $\mathrm{H}$, et al. Influence of root canal disinfectants on growth factor release from dentin. J Endod. 2015;41(3):363-8. doi:10.1016/j.joen.2014.11.021

5. Diogenes AR, Ruparel NB, Teixeira FB, Hargreaves KM. Translational science in disinfection for regenerative endodontics. J Endod. 2014;40(4 Suppl):S52-7. doi:10.1016/j.joen.2014.01.015

6. Smith AJ. Vitality of the dentin-pulp complex in health and disease: growth factors as key mediators. J Dent Educ. 2003;67(6):678-89.

7. Tjäderhane L, Koivumäki S, Pääkkönen V, Ilvesaro J, Soini Y, Salo T et al. Polarity of mature human odontoblasts. J Dent Res. 2013;92(11):1011-6. doi:10.1177/0022034513504783

8. Zhao S, Sloan AJ, Murray PE, Lumley PJ, Smith AJ. Ultrastructural localisation of TGF-beta exposure in dentine by chemical treatment. Histochem J. 2000;32(8):489-94. doi:10.1023/A:1004100518245

9. Demarco FF, Conde MC, Cavalcanti BN, Casagrande L, Sakai VT, Nör JE. Dental pulp tissue engineering. Braz Dent J. 2011;22(1):3-13. doi:10.1590/S0103-64402011000100001

10. He W, Zhang J, Niu Z, Yu Q, Wang Z, Zhang R et al. Regulatory interplay between NFIC and TGF- $\beta 1$ in apical papilla-derived stem cells. J Dent Res. 2014;93(5):496-501. doi:10.1177/0022034514525200

11. Howard C, Murray PE, Namerow KN. Dental pulp stem cell migration. J Endod. 2010;36(12):1963-6. doi:10.1016/j.joen.2010.08.046

12. Sakai VT, Cordeiro MM, Dong Z, Zhang Z, Zeitlin BD, Nör JE. Tooth slice/scaffold model of dental pulp tissue engineering. Adv Dent Res. 2011;23(3):325-32. doi:10.1177/0022034511405325

13. Johal S, Baumgartner JC, Marshall JG. Comparison of the antimicrobial efficacy of $1.3 \% \mathrm{NaOCl} /$ BioPure MTAD to $5.25 \% \mathrm{NaOCl} / 15 \%$ EDTA for root canal irrigation. J Endod. 2007;33(1):48-51. doi:10.1016/j.joen.2006.08.007
14. Cecchin D, Farina AP, Galafassi D, Barbizam JV, Corona SA, Carlini-Júnior B. Influence of sodium hypochlorite and edta on the microtensile bond strength of a self-etching adhesive system. J Appl Oral Sci. 2010;18(4):385-9. doi:10.1590/S1678-77572010000400011

15. Estrela C, Estrela CR, Barbin EL, Spanó JC, Marchesan MA, Pécora JD. Mechanism of action of sodium hypochlorite. Braz Dent J. 2002;13(2):113-7. doi:10.1590/S0103-64402002000200007

16. Estrela C, Estrela CR, Decurcio DA, Hollanda AC, Silva JA. Antimicrobial efficacy of ozonated water, gaseous ozone, sodium hypochlorite and chlorhexidine in infected human root canals. Int Endod J. 2007;40(2):85-93. doi:10.1111/j.1365-2591.2006.01185.x

17. Casagrande L, Demarco FF, Zhang Z, Araujo FB, Shi S, Nör JE. Dentin-derived BMP-2 and odontoblast differentiation. J Dent Res. 2010;89(6):603-8. doi:10.1177/0022034510364487

18. Calt S, Serper A. Smear layer removal by EGTA. J Endod. 2000;26(8):459-61. doi:10.1097/00004770-200008000-00007

19. Lee CP, Colombo JS, Ayre WN, Sloan AJ, Waddington RJ. Elucidating the cellular actions of demineralised dentine matrix extract on a clonal dental pulp stem cell population in orchestrating dental tissue repair. J Tissue Eng. 2015;6: 2041731415586318. doi:10.1177/2041731415586318

20. Cordeiro MM, Dong Z, Kaneko T, Zhang Z, Miyazawa M, Shi $S$ et al. Dental pulp tissue engineering with stem cells from exfoliated deciduous teeth. J Endod. 2008;34(8):962-9. doi:10.1016/j.joen.2008.04.009

21. Gonçalves SB, Dong Z, Bramante CM, Holland GR, Smith AJ, Nör JE. Tooth slice-based models for the study of human dental pulp angiogenesis. J Endod. 2007;33(7):811-4. doi:10.1016/j.joen.2007.03.012

22. Sakai VT, Zhang Z, Dong Z, Neiva KG, Machado MA, Shi $S$ et al. SHED differentiate into functional odontoblasts and endothelium. J Dent Res. 2010;89(8):791-6. doi:10.1177/0022034510368647

23. Miura M, Gronthos S, Zhao M, Lu B, Fisher LW, Robey PG et al. SHED: stem cells from human exfoliated deciduous teeth. Proc Natl Acad Sci U S A. 2003;100(10):5807-12. doi:10.1073/pnas.0937635100

24. Mathieu S, Jeanneau C, Sheibat-Othman N, Kalaji N, Fessi H, About I. Usefulness of controlled release of growth factors in investigating the early events of dentin-pulp regeneration. J Endod. 2013;39(2):228-35. doi:10.1016/j.joen.2012.11.007

25. Galler KM. Clinical procedures for revitalization: current knowledge and considerations. Int Endod J. 2016;49(10):926-36. doi:10.1111/iej.12606 